\title{
Mass Balance of PAHs at the Scale of the Seine River Basin
}

\author{
D. Gateuille, J. Gasperi, C. Briand, E. Guigon, F. Alliot, M. Blanchard, \\ M.-J. Teil, M. Chevreuil, V. Rocher, S. Azimi, D. Thevenot, R. Moilleron, \\ J.-M. Brignon, M. Meybeck, and J.-M. Mouchel
}

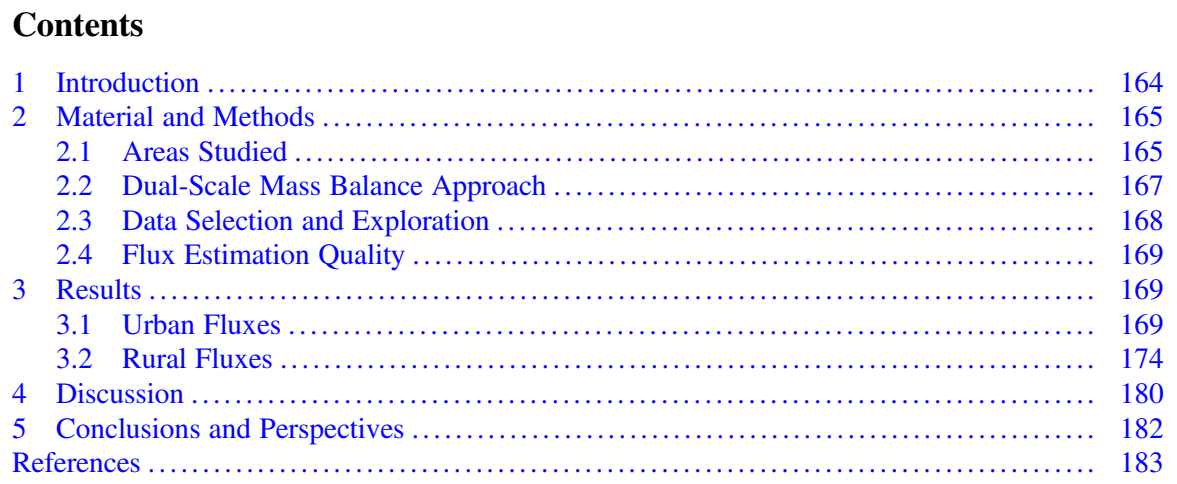

The copyright year of the original version of this chapter was corrected from 2019 to 2020 . A correction to this chapter can be found at https://doi.org/10.1007/698_2020_667

D. Gateuille $(\bowtie)$

Université Paris-Est, Laboratoire LEESU, Champs-sur-Marne, France

Université Savoie Mont Blanc, Laboratoire LCME, Chambéry, France e-mail: david.gateuille@univ-smb.fr

J. Gasperi, C. Briand, D. Thevenot, and R. Moilleron

Université Paris-Est, Laboratoire LEESU, Champs-sur-Marne, France

E. Guigon, F. Alliot, M. Blanchard, M.-J. Teil, M. Chevreuil, M. Meybeck, and J.-M. Mouchel Sorbonne Université, CNRS, EPHE, PSL University, UMR Metis, Paris, France

V. Rocher and S. Azimi

SIAAP - Direction Innovation et Environnement, Colombes, France

J.-M. Brignon

Institut national de l'environnement industriel et des risques, Verneuil-en-Halatte, France 


\begin{abstract}
The Seine River basin (France) is representative of the large urbanised catchments $\left(78,650 \mathrm{~km}^{2}\right)$ located in Northwestern Europe. As such, it is highly impacted by anthropogenic activities and their associated emissions of pollutants such as polycyclic aromatic hydrocarbons (PAHs). These compounds, originating from household heating and road traffic, are responsible for serious environmental issues across the basin. This study aims at establishing and using mass balance analyses of PAHs at the Seine River basin scale as an efficient tool for understanding PAH pathways in the environment. A dual-scale approach (urban vs. rural areas) was used successfully, and mass balances provided useful knowledge on the environmental fate of PAHs. In urban areas, runoff and domestic and industrial discharges contributed similarly to the PAH supply to the sewer system. During the wastewater treatment process, PAHs were mainly eliminated through sludge removal. At the basin scale, substantial amounts of PAHs were quantified in soils, and the limited annual inputs and outputs through atmospheric deposition and soil erosion, respectively, suggest that these compounds have long residence times within the basin. While wastewater and runoff discharges from urban areas account for a substantial part of PAH urban fluxes to the Seine River, soil erosion seems to be the predominant contributor at the basin scale. Overall, the PAH flux at the basin outlet was greater than supplies, suggesting that the Seine River system may currently be undergoing a decontamination phase.
\end{abstract}

Keywords eLTER, Environmental fluxes, Mass balance, PIREN-Seine, Pollutant fate, Polycyclic aromatic hydrocarbons, Seine River basin, Urban fluxes, Zone Atelier Seine

\title{
1 Introduction
}

The Seine River basin $\left(78,650 \mathrm{~km}^{2}\right)$, located in Northwestern France, has been studied since 1990 within the PIREN-Seine programme and can be considered as representative of river basins exposed to the impacts of intense human activity $[1,2]$. This basin accommodates a combination of strong human pressures (17 million people, with approximately 10 million aggregated within the Paris conurbation; $30 \%$ of French industrial and agricultural production) with very limited dilution by the Seine River, due to its low flow (median flow, $300 \mathrm{~m}^{3} \mathrm{~s}^{-1}$ ); the basin therefore is structurally vulnerable, and its river course downstream of the Paris conurbation shows heavy contamination [1]. Similarly to other river basins in Europe, the SeineNormandie Water Agency reported that more than 50\% of waterbodies were in poor chemical status, mostly due to polycyclic aromatic hydrocarbons (PAHs).

PAHs are a group of widespread organic compounds. Due to their high toxicity and their known carcinogenic properties for animals and humans [3], they constitute an environmental threat. Besides natural sources, PAHs are mainly emitted by anthropogenic activities such as combustion of fuels, coal and biomass or the use of bitumen- and petroleum-containing products [4] or by domestic sources such as tobacco smoke and cooking [5]. In Europe, PAHs (nine congeners) were included 
in the initial list of 33 priority pollutants of the Water Framework Directive (WFD) (2000/60/EC), establishing the water policy at the river basin scale. In the European Union, water policy is based on a number of specific directives defining communitywide emission limit values and quality objectives in surface and coastal waters. The implementation of such directives requires member states to reach "good chemical" status. Based on the last report (2012, European waters - assessment of status and pressures, EEA Report), PAHs appear as a widespread cause of poor status in rivers and are identified as problematic by 11 member states.

In this context, accurate knowledge of PAH sources and fate in aquatic systems at the catchment scale was proven necessary to (1) better assess the spatial and temporal dynamics of PAH input and output fluxes over an entire catchment and (2) identify possible pollutant reduction measures. Although numerous studies were carried out on PAHs in different environmental compartments, i.e. total atmospheric deposition [6], soils [7], surface water [8] or sediment [9], there have been few attempts in the literature to draw up a total PAH budget at the catchment scale [10-14]. The published studies did not integrate all environment compartments, nor were they carried out considering the spatial urbanisation variability across the catchment at the scale of a major river basin.

\section{Material and Methods}

This study was based on the integrative approach previously developed to investigate the heavy metal contamination within the Seine River basin $[1,2]$. To study the fate of PAHs in this basin, contamination data in various environmental compartments were gathered from previous studies, and the mass balance was established at two nested scales. The calculations of individual fluxes are detailed below. To evaluate the robustness of the mass balance calculation, each flux was associated with both an uncertainty and a grade assessing the quality of the database used to estimate such fluxes.

\subsection{Areas Studied}

The PAH fluxes were assessed at two complementary scales: the Paris conurbation and the rural areas (Fig. 1).

All parameters concerning the Paris conurbation sewer system were provided by the SIAAP (Paris conurbation wastewater treatment authority). Hydrological data and information about the dredging operations were provided by the SeineNormandie Water Agency (AESN), the French department of waterways (VNF) or the Île-de-France Regional Department for Equipment and Planning (DRIEAIF). The meteorological parameters came from either the studies cited herein or MétéoFrance. Land use was determined using ArcMap (ver10.5) with the Corine Land Cover 2012 database. Information about the road network was obtained from the Route $500^{\circledR}$ database published by the French National Geographic Institute (IGN).

The Paris conurbation covered more than $1,830 \mathrm{~km}^{2}$ including the most populated parts of the Seine River basin. The sewer system annually collects $900 \mathrm{Mm}^{3}$ of water 


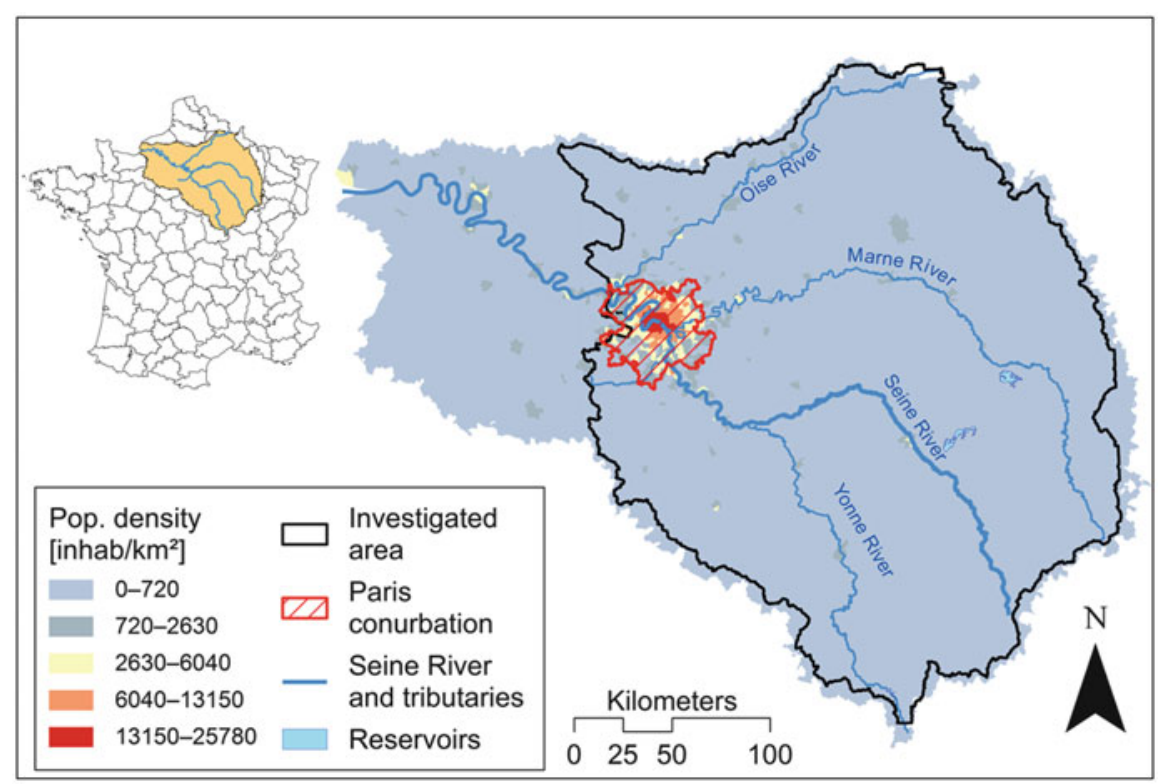

Fig. 1 Map delimiting the two areas considered in the dual approach. The black line delimits the investigated area including the uppermost parts of the basin downstream to the city of Triel-sur-Seine. The red hatched zone indicates the Paris conurbation

including industrial and domestic wastewater (about ten million inhabitants), runoff, parasite water, groundwater infiltration and street cleaning water. Depending on the location, the Paris conurbation was drained by combined sewers $(30 \%$ of the surface area), separate sewers (56\%) or a combination of separate and combined sewers $(14 \%)$. However, due to the high population density in the historical centre, the daily volume of wastewater mainly originated from combined sewers (75\%). In 2014, over 112,000 tons dry weight of sludge was produced during wastewater treatment. It was used for energy purposes (41\%), spread over agricultural lands (29\%), composted further before spreading (22\%) or stored as hazardous material (8\%) [15]. Across the conurbation, an average of $24 \%$ of the surface was impervious, while the remaining had a limited infiltration capacity leading to a mean runoff coefficient of 0.7 [16]. In 2014, the annual rainfall over the Paris conurbation was $713 \mathrm{~mm}$.

The entire investigated area had a surface of $61,300 \mathrm{~km}^{2}(78 \%$ of the whole Seine River basin area), mainly covered by agricultural land (66\%), forested land (27\%) and urban areas (7\%). It accommodated $82 \%$ of the entire population of the Seine River basin. The outlet considered (Triel-sur-Seine) of the investigated area was chosen far enough downstream of the WWTP discharges to include the Paris conurbation emissions into the Seine River flux. However, it was also set upstream of the Seine River mouth in order to avoid tidal effects. The mass balances were established using the meteorological and hydrological parameters (e.g. Seine River discharge, suspended sediment concentrations, etc.) measured in 2014. This year was selected because of its representativeness in terms of meteorology and hydrology. The annual average rainfall was $743 \mathrm{~mm}$, and the mean discharge of 
the Seine River at Paris was $325 \mathrm{~m}^{3} \mathrm{~s}^{-1}\left(321 \mathrm{~m}^{3} \mathrm{~s}^{-1}\right.$ for the 2006-2018 period). A high-flow period was observed from December to late March, and the rest of the year was characterised by a low flow rate. The annual water and suspended sediment discharges at the outlet of the investigated area were estimated at $1.4 \times 10^{10} \mathrm{~m}^{3} \mathrm{year}^{-1}$ and $3.1 \times 10^{5}$ tons year $^{-1}$, respectively, based on measurements on both the Seine River at Paris and the Oise River. Previous studies on the sediment yield in the Seine River basin [17, 18] showed that the average erosion rates over agricultural lands, forests and urban areas were assumed equal to 18.4, 2.0 and 0.9 tons $\mathrm{km}^{-2}$ year $^{-1}$, respectively. Thus, the estimated sediment yield to the rivers at the investigated area scale was $7.6 \times 10^{5}$ tons year $^{-1}$, in good agreement with the sediment flux estimated at the outlet considering that a fraction of eroded sediment was deposited on the river bed [18]. Approximately $1.0 \times 10^{5}$ tons year $^{-1}$ of sediment are trapped in the reservoirs or on the floodplains upstream of Paris [2]. In addition, $1.2 \times 10^{5}$ tons year $^{-1}$ of river bed sediment were removed during dredging operations. Either the collected sediment was used for agriculture or bank reinforcement or it was sent to landfill when the contaminant concentrations exceed the legal standards. A mass balance analysis of the sediment flux considering the erosion rate, the deposition rate on the floodplain and in the reservoirs and the sediment flux at the outlet of the basin provided an estimation of the amount of sediment stored within the river bed: $2.3 \times 10^{5}$ tons $_{\text {year }}{ }^{-1}$.

\subsection{Dual-Scale Mass Balance Approach}

To quantify the fluxes at the investigated area scale, a two-step method was applied. First, all urban fluxes were estimated for the Paris conurbation that constitutes a well-defined and densely urbanised area located in the downstream sector of the investigated catchment. Thus, the urban fluxes at the basin scale were assessed either (1) using the same calculation method as for the Paris conurbation but with an adapted database including all the data available for the investigated area or (2) multiplying the flux estimated for the Paris conurbation by 1.4 considering the change in the population from 10 (Paris conurbation) to 14 million inhabitants (the entire investigated area). This dual approach was chosen as it reduced the number of complex retroactions, thereby facilitating the consideration of a high level of detail in the flux charts. In the following, the fluxes are named according to their estimation method, namely, from direct measurement $(\mathrm{F})$, economic data $(\mathrm{E})$ or a combination of other fluxes (D).

Urban fluxes included the emissions to the atmosphere (E5a, E5b, E6), the atmospheric deposition (F12) and the runoff fluxes (F12e, F12f). The domestic and industrial releases to the sewer system (F22a, E22h) or to the Seine River (E22g) were also considered. The discharges of the sewer system to the river system during dry weather (F22d) or wet weather (F22c) and removal during sewer deposit cleaning processes (F22i) were taken into account. Special attention was paid to the WWTP-related fluxes including the inflow from the sewer system (F22e), the outflow to the Seine River (F22f) and urban sludge (F13a, F13b, F13c, E13d). 
Rural fluxes included atmospheric fallout over agricultural land (F10) and the spreading of urban sludge (F13) or sediment (F25b) from river dredging. In addition, the inputs to forested soils through atmospheric deposition (F11a) and the forest filter effect (F11b) [19] were estimated. Road runoff outside of urban areas (E14) was also considered. The stocks in agricultural and forested soils were quantified (S10, S11). The erosion fluxes from agricultural, forested, urban and industrial land were estimated (F15, F16, F17 and F18) and combined to quantify the inputs into the Seine River (F19). In addition, storage in the reservoirs (F23a), onto the river bed (F23b) and on the floodplains (F24) was estimated as was the removal related to sediment dredging operations (F25a). Finally, the flux at the outlet of the investigated area was estimated (F21).

\subsection{Data Selection and Exploration}

The PAH content databases used to compute the flux estimations were gathered from about 40 previous studies investigating PAH contamination across the Seine River basin. Whenever possible, only data collected within the investigated area (Fig. 1) were considered. Otherwise, databases from other studies in France or Western Europe were used, therefore weakening the estimation of the quality grade (see below). A specific effort was made to avoid data duplication by crosschecking the sampling sites and dates in the various studies. When only summarised data were available, data were reconstructed assuming a log-normal distribution.

Fluxes were estimated for the sum of 15 compounds $(\Sigma 15)$ including acenaphthylene [ACY], acenaphthene [ACE], fluorene [FLU], phenanthrene [PHE], anthracene [ANT], fluoranthene [FLH], pyrene [PYR], chrysene [CHR], benzo(a)anthracene [BaA], benzo (b)fluoranthene $[\mathrm{BbF}]$, benzo(k)fluoranthene $[\mathrm{BkF}]$, benzo(a)pyrene $[\mathrm{BaP}]$, indeno(c,d) pyrene [IcdP], dibenzo(a,h)anthracene [DahA] and benzo(g,h,i)perylene [BghiP]. When data for some compounds were lacking, fluxes were quantified for the sum of the remaining compounds, and the missing compounds are specified in the text.

Data were systematically tested for spatial or temporal trends and for their relationship with external factors such as meteorological parameters. Whenever a parameter had a significant influence on the PAH contents, the flux calculation was improved by integrating this parameter into the calculation. Statistical investigations were made using $\mathrm{R}$ (ver3.4.4; $\mathrm{R}$ Core Team, 2016) software with the RStudio interface (v1.1.453). Except for the fluxes estimated from economic data, the calculations were carried out by multiplying the flux of the matrix considered (e.g. runoff) by randomly drawn PAH content values in the appropriate database. The estimation was made such that the number of draws was equal to the number of samples in the database and draws were made with replacements. Thus, each sample had the same probability of occurrence. To ensure a representative value of the flux and to quantify the uncertainties, the calculation was repeated 10,000 times. Then the flux value and its associated mathematical uncertainty were estimated as the mean value and the standard deviation over the 10,000 computations after having ensured that the calculations converged. 


\subsection{Flux Estimation Quality}

The mathematical uncertainties estimated as previously described failed to reflect the quality of the database used for the flux calculation. To express this quality, grades were attributed according to five parameters including the database size, the number of studies, the sampling date in comparison with 2014, the spatial and temporal representativeness of the samples and the quality of the parameters that were used in the estimations (e.g. runoff). Each parameter was rated from 0 to 4 (low to high quality). The global quality grade was estimated as the lowest rate for individual parameters. The fluxes based on a numeric model or economic data were awarded a quality grade of 0 because no actual measurement could back up the results.

\section{Results}

\subsection{Urban Fluxes}

All urban fluxes are summarised in Fig. 2.

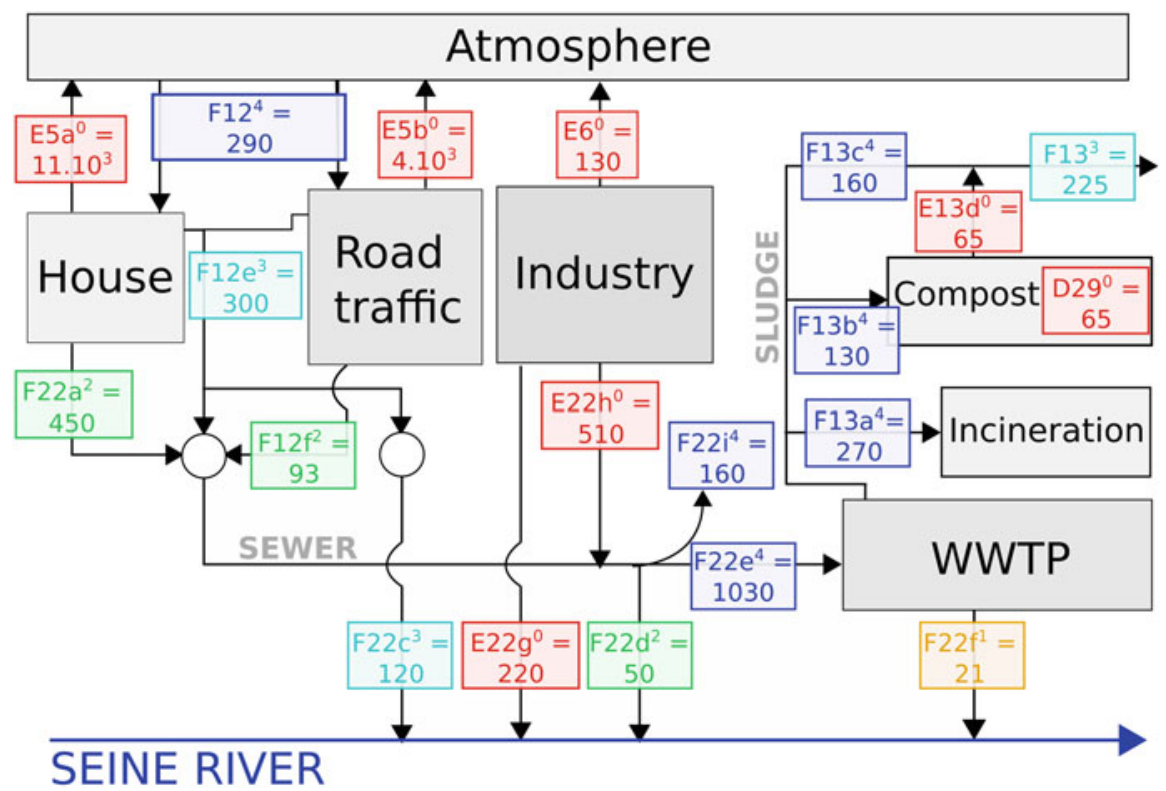

Fig. 2 PAH urban fluxes $\left(\mathrm{kg}_{\mathrm{year}}{ }^{-1}\right)$ in the Paris conurbation. $F$ flux calculation based on actual PAH content measurement in the area studied, $E$ based on economic data or pollutant quantification in a similar environment, $D$ calculated from the linear combination of other fluxes. Quality grade in superscript from 0 (worst, in red) to 4 (best, deep blue). E5a house heating, E5b road traffic, E6 industrial emissions, $F 12$ atmospheric deposition, $F 12 e$ runoff, $F 12 f$ street cleaning, $F 13$ sludge spreading, F13a sludge incineration, F13b composted sludge, E13d compost remains, F22a domestic wastewater, $F 22 c$ untreated runoff, $F 22 d$ untreated wastewater, $F 22 e$ WWTP inflow, $F 22 f$ WWTP effluent, $E 22 g$ industrial releases to the river, $E 22 h$ industrial discharge to the sewer system, F22i sewer deposit removal, D29 compost degradation 


\subsubsection{Emissions to the Atmosphere}

Urban and industrial PAH emissions to the atmosphere were estimated based on the INERIS (French National Institute for Environmental Technology and Hazards) database. A recurrent spatial inventory of atmospheric pollutant emissions including PAHs has been made since 2003 by the INERIS. It includes emissions from all reported sources, whether anthropogenic or natural. Since source types were specified, the PAH emissions related to household heating, road traffic and industrial activities were estimated independently. Thus, household heating and road traffic, respectively, amounted to E5a $=11$ tons $\operatorname{year}^{-1}(\Sigma 16$, naphthalene included) and $\mathrm{E} 5 \mathrm{~b}=4$ tons year $^{-1}(\Sigma 16)$ of PAHs, leading to total urban emissions of $\mathrm{E} 5=15$ tons year ${ }^{-1}(\Sigma 16)$. At the same time, industries emitted E6 $=130 \mathrm{~kg} \mathrm{year}^{-1}$ ( 16$)$. As for all fluxes that were not supported by environmental data, the quality grade was set at 0 . In particular, although the source inventory was quite exhaustive, the emission coefficients used to quantify the emissions could hardly be confirmed. Therefore, the value of the estimated flux is provided as a rough estimate. However, the order of magnitude was in agreement with a study reported by the French Center for Atmospheric Pollution Study (CITEPA) that estimated the emissions of eight PAHs (FLH, BaA, BaP, BbF, BkF, BghiP, IcdP and DahA) at 72 tons year $^{-1}$ for all of metropolitan France (a sevenfold higher population).

\subsubsection{Atmospheric Deposition}

To quantify the atmospheric fallout over the Paris conurbation, PAH contents were taken from four studies gathering 95 bulk deposition samples collected between 2002 and 2014 [6, 20-22]. The seasonality in the atmospheric fallout was instigated, and the concentrations of PAHs in the bulk deposition displayed significant monthly changes (Kruskal-Wallis test, $p$-value $<0.05$ ). The rise was related to household heating during winter leading to significantly higher PAH emissions. The annual deposition was consequently estimated as the sum over the cold and the warm periods of the rainwater volumes over 4-day periods multiplied by random concentration values drawn in the corresponding database. The 4-day period was chosen to ensure a drawn probability for each sample of approximately one out of the number of samples in the database $(n=95)$. Following this method, the atmospheric deposition totalled F12 = $290 \pm 70 \mathrm{~kg}_{\text {year }}{ }^{-1}(\Sigma 15)$. This fallout flux $\left(160 \mathrm{~g} \mathrm{~km}^{-2}\right.$ year $\left.^{-1}\right)$ was lower than previously reported values within the range 208-234 $\mathrm{g} \mathrm{km}^{-2}$ year $^{-1}[12,23]$ measured over urban areas across the Seine River basin from 1999 to 2002 . These results suggest a decrease in the atmospheric deposition over the past few decades, in agreement with the overall reduction of about 44\% in PAH emissions reported by the CITEPA between 2000 and 2014. Because the database gathered a large number of samples representative in time and space of the PAH atmospheric deposition in the Seine River basin, the flux estimation was awarded the quality grade of 4 . 


\subsubsection{Runoff}

The PAH flux related to runoff on roads and roofs (F12e) was quantified considering the volume of runoff collected in the sewer system. To estimate this flux, the PAH concentrations were gathered from four studies depicting 31 samples collected in separate sewer systems of urban areas [10, 24-26]. The samples covered an extended area across the Paris conurbation, providing a good spatial representativeness of the database. Moreover, they were in good agreement with previously reported values for similar urban or suburban areas [27, 28]. However, the temporal representativeness was not as good. Indeed, samples were collected at various times over the year, but the relationship between PAH concentrations and the characteristics of the rain event considered (rainfall intensity or duration of the previous dry periods) could not be investigated. Consequently, this flux was estimated as the sum over the year of 12-day periods of runoff volumes multiplied by PAH concentrations randomly drawn within the runoff database. The flux totalled $\mathrm{F} 12 \mathrm{e}=300 \pm 40 \mathrm{~kg} \mathrm{year}^{-1}(\Sigma 15)$. This result was in good agreement with fluxes reported for other French urban areas [29]. However, the quality grade of this flux was reduced to 3 because of the lack of information on the temporal changes in the runoff contamination.

In addition, the PAH flux during the street cleaning process (F12f) was quantified. According to the SIAAP, the amount of water used for street cleaning reached $59 \mathrm{Mm}^{3}$ year ${ }^{-1}$. A previous study showed that the PAH concentration in water samples ranged from 0.1 to $2.2 \mu \mathrm{g} \mathrm{L}^{-1}(\Sigma 13)$ [30]. This study used data from 21 samples collected at various places within the Paris city limits. Although the spatial database was spatially representative, all samples were collected from May to June 2002, and neither temporal changes nor the influence of meteorological parameters could be investigated. Consequently, and although the order of magnitude of the contamination was supported by the concentrations reported in runoff samples, the quality rate was downgraded to 2 . The flux estimated in this way was F12f $=93 \pm 3 \mathrm{~kg} \mathrm{year}^{-1}$ ( $\Sigma 16$, naphthalene included), and it amounted to $32 \%$ of the atmospheric deposition and $29 \%$ of the PAH runoff from roads and roofs. However, the influence of meteorological parameters could not be tested, and a redundancy between F12e (street runoff) and F12f (street cleaning) cannot be excluded because both remobilise pollutants from roads.

\subsubsection{Domestic and Industrial Wastewater}

The flux related to domestic wastewater (F22a) was quantified using 35 measurements either in domestic effluents or in combined sewers during dry weather periods $[30,31]$. Specific attention was paid to using only samples collected close to domestic sources to avoid dilution by infiltration waters. Using data from combined sewers provided a better spatial representativeness, especially within the city of Paris itself, where there were exclusively combined sewers. However, this might have 
led to a flux overestimation because part of the pollution within the combined sewer is due to the remobilisation of runoff contaminants deposited during wet weather. Consequently, the quality rate was downgraded to 2 . The flux was estimated by summing the daily volume of domestic wastewater over the year multiplied by a concentration value randomly drawn within the database; this led to an averaged value of F22a $=450 \pm 50 \mathrm{~kg} \mathrm{year}^{-1}(\Sigma 15)$. However, the measurement of the PAH concentrations in domestic wastewater alone collected in house disposals would be necessary to better assess this flux.

According to the SIAAP, industries discharged a volume of $25 \mathrm{Mm}^{3}$ year ${ }^{-1}$. Given that no data on PAH concentration in industrial wastewater in the Seine River basin was available, the flux was estimated using data from the literature [32] because it was reported to be similar to that measured in the Paris area [33]. The PAH flux released by industries into the sewer system was E22h $=510 \pm 220 \mathrm{~kg} \mathrm{year}^{-1}(\Sigma 15)$. However, this result could not be backed up by actual measurements in the Paris conurbation, and the quality rate was downgraded to 0 . In addition, $30 \%$ of industrial wastewater was released directly into the Seine River without any preliminary treatment [2], leading to a direct discharge of PAHs into the Seine River of E22 $\mathrm{g}=220 \pm 90 \mathrm{~kg} \mathrm{year}^{-1}$ $(\Sigma 15)$.

\subsubsection{Discharges from the Sewer System}

During the past few years, the chemical quality of storm water in the Paris area has been extensively investigated, especially within the OPUR research programme $[10,26]$. The resulting database was described in "Runoff" above, leading to the same quality grade (3). The volume of runoff water collected in the separate sewer system was $95 \mathrm{Mm}^{3}$ for 2014. Based on these data, the flux of PAHs directly discharged into the Seine River by storm water was F22c $=120 \pm 12 \mathrm{~kg} \mathrm{year}^{-1}$ $(\Sigma 15)$.

PAH input into the river system also occurred from combined sewers during storms or during sewer system dysfunction. In $2014,20.5 \mathrm{Mm}^{3}$ of combined sewer overflows (wet weather), and $18.2 \mathrm{Mm}^{3}$ of untreated wastewater (dry weather) were discharged. To quantify the flux of PAHs related to these overflow events, concentrations of PAHs in samples collected in combined sewers were matched to the corresponding water volumes depending on the weather conditions. The databases were constituted of 22 samples from three different studies [24, 34, 35] for dry weather conditions and 99 samples from five studies [16, 24, 30, 36, 37] for wet weather conditions. A total flux of $\mathrm{F} 22 \mathrm{~d}=50 \pm 4 \mathrm{~kg}^{\text {year }}{ }^{-1}(\Sigma 15)$ was estimated, nearly $80 \%$ being released during wet weather conditions. The database used to quantify this flux summarised data from various sites and was therefore spatially representative. However, the lack of information on intra-event variability in PAH concentrations resulted in a quality grade of 2 . 
The last PAH flux related to the sewer system was the removal of highly contaminated sewer deposits during pipe cleaning. In 2014, 7,170 tons of sediment was removed from the sewer system. The contamination of sewer sediment has been documented in four studies [31, 38-40] and by the Paris Sanitation Department between 2000 and 2014. The corresponding database gathered PAH measurements from 406 samples, thereby ensuring good spatial and temporal representativeness. Consequently, the flux estimation was awarded a quality grade of 4 . The PAH flux related to sediment cleaning in the sewer system was F22i $=160 \pm 10 \mathrm{~kg} \mathrm{year}^{-1}$ $(\Sigma 15)$. Since sewer sediment is not suitable for amending agricultural land, it was stored as hazardous material.

\subsubsection{Wastewater Treatment Plants}

To quantify the total flux of PAHs entering WWTPs (F22e), the period investigated was divided between dry weather periods (208 days in 2014, average inflow, $2.2 \mathrm{Mm}^{3}$ day $^{-1}$ ) and wet weather periods (157 days, inflow, $2.8 \mathrm{Mm}^{3}$ day $^{-1}$ ). The $\mathrm{PAH}$ input was estimated as the daily collected water volumes from each sewer type multiplied by corresponding PAH concentrations measured in separate or combined sewers. For this estimation, care was taken to use data from samples collected at downstream parts of the sewer system. It was assumed that these samples were representative of the mix of waters originating from different sources including infiltration water. Consequently, entirely distinct databases were used to compute the F22a, E22h, F12e and F22e fluxes. The data of 121 samples from nine studies, including wastewater from the four main WWTPs, were used. The annual load of PAHs was F22e $=1,030 \pm 50 \mathrm{~kg} \mathrm{year}^{-1}(\Sigma 15)$. The order of magnitude was also consistent with a previous study that reported an annual flux of about $476 \mathrm{~kg} \mathrm{year}^{-1}$ for six compounds (FLH, BaP, BbF, BkF, BghiP and IcdP) [36]. Consequently, this flux estimation was awarded a quality grade of 4 .

Once they have entered WWTPs, PAHs may be degraded during the treatment process, removed from the effluent through sorption onto sludge or discharged into the Seine River at the outlet of the WWTP. To quantify the amount of PAHs removed by the sludge removal process, the daily mass of sludge was multiplied by the random PAH contents measured in this matrix. The database comprised data from a previous study [36] or was provided by the SIAAP. It gathered data for 16 samples collected at three WWTPs treating $74 \%$ of the Paris conurbation population. Thus, the annual PAH amount removed from the WWTP was $560 \pm 40 \mathrm{~kg} \mathrm{year}^{-1}(\Sigma 13, \mathrm{ACE}$ and ACY excluded). The largest part was reduced by the sludge thermal process $\left(\mathrm{F} 13 \mathrm{a}=270 \pm 20 \mathrm{~kg} \mathrm{year}^{-1}, \Sigma 13\right)$, the rest being either composted $\left(\mathrm{F} 13 \mathrm{~b}=130 \pm 10 \mathrm{~kg}\right.$ year $\left.^{-1}, \Sigma 13\right)$ or spread over agricultural land without further treatment $\left(\mathrm{F} 13 \mathrm{c}=160 \pm 10 \mathrm{~kg} \mathrm{year}^{-1}, \Sigma 13\right)$. Considering that PAH content in sludge has been steady over the past few years [15], good spatial and temporal representativeness was expected, and the estimations of sludge-related fluxes were awarded a quality grade of 4 . No data for PAHs in composted sludge was available (E13d). Therefore, the PAH degradation rates during the composting 
process reported elsewhere for French sludge [41] were used to quantify the flux of the remaining PAHs $\left(\mathrm{E} 13 \mathrm{~d}=65 \mathrm{~kg} \mathrm{year}^{-1}, \Sigma 13\right)$ after the composting process. Given that the composted sludge was also spread, the total flux of PAHs towards agricultural lands totalled $\mathrm{F} 13=\mathrm{F} 13 \mathrm{c}+\mathrm{E} 13 \mathrm{~d}=225 \mathrm{~kg} \mathrm{year}^{-1}(\Sigma 13)$.

Finally, the annual load of PAHs released to the Seine River by the WWTPs was estimated based on PAH concentrations measured in the effluent and considering the annual volume of treated water discharged into the river. Although PAH concentrations in WWTP effluent have been monitored for many years, only six samples collected at two WWTP outlets [34] were available. When compared to previous studies elsewhere in Europe [42-44], significant differences were observed (Wilcoxon-Mann-Whitney test, $p<0.05$ ) for similar wastewater treatment processes. This result may be due to the high efficiency in the suspended matter removal at one of the WWTPs (Seine-Centre). Based on data from this study, the PAH flux related to WWTP effluent discharge reached F22f $=21 \pm 4.1 \mathrm{~kg}_{\text {year }}{ }^{-1}$ $(\Sigma 15)$. Because of the lack of data and the differences that were observed between these data and the literature, the quality rate of this estimation was downgraded to 1 .

\subsection{Rural Fluxes}

All the rural fluxes are summarised in Fig. 3.

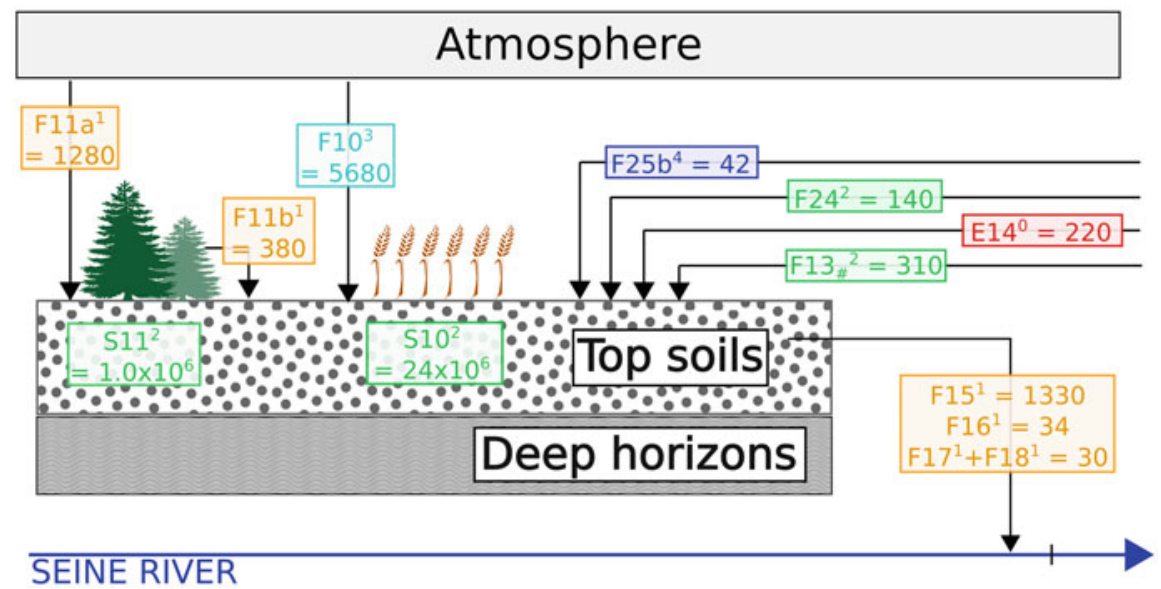

Fig. 3 PAH rural fluxes $\left(\mathrm{kg} \mathrm{year}^{-1}\right)$ in the Seine River basin. $F$ flux calculation based on actual PAH content measurements in the Seine River basin, $E$ based on economic data or pollutant quantification in similar environment, $F_{\#}$ or $E_{\#}$ flux based on the estimation at the Paris conurbation scale. Quality grade in superscript from 0 (worst, in red) to 4 (best, deep blue). F10 and F11a atmospheric deposit over agricultural and forests, $F 11 b$ forest filter effect, $F 13$ and $F 25 b$ spreading of urban sludge and sediment from river dredging, E14 road runoff, F15, F16, F17 and F18 erosion from agricultural, forested, urban and industrial lands, respectively, F24 flood deposits, $S 10$ and $S 11$ stocks $(\mathrm{kg})$ in agricultural and forested areas 


\subsubsection{Atmospheric Deposition}

To quantify the PAH atmospheric deposition on rural areas, the investigated area was divided by discriminating between agricultural and forested land. Indeed, specific deposition processes over vegetated areas have been previously reported due to the forest filter effect $[19,45,46]$, thereby justifying different approaches. To quantify the fallout flux over agricultural areas, a large database gathering 92 samples from two studies was available [11, 47]. A significant difference was measured between the warm and cold periods (Wilcoxon-Mann-Whitney test, $p<0.0001$ ). This temporal variation was included in the flux estimation, as for F12. Thus, the atmospheric deposit over agricultural land reached F10 $=5,680 \pm 860 \mathrm{~kg} \mathrm{year}^{-1}$ $(\Sigma 15)$. Because of the representative database, this estimation was awarded a grade of 3. To estimate the atmospheric deposition over forests, only the data of five samples from one study were available [47]. The same calculation method as for other fallout fluxes (F12 and F10) was used, although not enough data were available to distinguish between the warm and cold period fallouts. Thus, the atmospheric deposition over forested areas reached $1,280 \pm 240 \mathrm{~kg} \mathrm{year}^{-1}(\Sigma 15)$. Due to the number of samples, the spatial and temporal representativeness was limited, however. Consequently, the quality rate of this flux estimation was downgraded to 1 . The forest filter effect was quantified based on the following values reported in the literature: average litter production of $390 \pm 50 \mathrm{~g} \mathrm{~m}^{-2}$ year ${ }^{-1}[45,48]$ and average leaf contaminations of $30 \pm 20 \mathrm{ng} \mathrm{g}^{-1}$ in remote forests [49, 50]. In addition, data from a previous study gathering 77 samples collected within the Seine River basin in forests directly exposed to PAH anthropogenic sources, including roads, were used [51]. Thus, the annual flux related to defoliation was F11b $=380 \pm 130 \mathrm{~kg} \mathrm{year}^{-1}$ ( $\Sigma 15)$. Since the remote forest contamination could not be supported by actual measurement, the flux quantification was awarded a grade of 1 .

\subsubsection{Road Runoff Outside of Urban Areas}

An additional runoff flux specific to the road network outside of urban areas was estimated. The surface concerned was estimated from the IGN database based on the road length and number of lanes provided. The road surface totalled $236 \mathrm{~km}^{2}$ in the investigated area, and a runoff coefficient of 0.9 was assumed. Since no data were available for rural road runoff, this volume was matched to the database of PAH concentrations in urban runoff water $(n=31)$, and the flux totalled $\mathrm{E} 14=220 \pm 30 \mathrm{~kg} \mathrm{year}^{-1}$. This flux reached E14 $=310 \pm 50 \mathrm{~kg} \mathrm{year}^{-1}$ when considering runoff flux in urban areas ending up in permeable soils. However, this database was representative of a rural environment, and this quantification was awarded a grade of 0 . 


\subsubsection{Stocks in Soils}

Due to their lipophilic properties, PAHs are mainly stored at the surface layer of soils [52]; consequently, the contamination depth depends on land use. For undisturbed soils such as forests, previous studies have shown that PAHs were mainly concentrated within the $8-10 \mathrm{~cm}$ of the topmost layer of soil [7, 53]. In agricultural areas, regular ploughing usually resulted in homogenisation of the physico-chemical properties of the surface layer [54], and the PAH content was assumed to be constant through the ploughed layer. In the Seine River basin, a 25-cm-deep contaminated layer was assumed. Therefore, the masses of contaminated soils were estimated as the product of the surface considered by the contamination depth by an average dry density of $1,350 \mathrm{~kg} \mathrm{~m}^{-3}$ [7]. Concerning the stocks in the urban and industrial areas, only the permeable fraction of the surface was expected to accumulate PAHs and was therefore taken into account. Since the thickness of the contaminated layer varied greatly depending on the site's history, an average value of $10 \mathrm{~cm}$ was used, as for undisturbed areas. Consequently, the estimation only constituted a lower limit of the PAH stocks in urban areas. Contaminant stocks were estimated by multiplying the masses of soils by random values of PAH contents drawn among 130 samples from two studies [7, 55]. A significant difference was measured between the soil PAH contents depending on their land use (Wilcoxon-MannWhitney test, $p<0.0001$ ), especially between forest and agricultural samples and urban and industrial samples. The samples collected in forested and agricultural areas underwent an additional procedure to discriminate between the samples depending on their distance to the road network with a $150-\mathrm{m}$ threshold. Indeed, previous studies reported specific traffic-related contamination within this range $[7,56]$. The stocks on both sides were quantified independently. Thus, 22\% of agricultural land and $13 \%$ of forest area were situated within the critical distance to the road network. The PAH stocks in agricultural lands reached $\mathrm{S} 10=24 \pm 17 \times 10^{6} \mathrm{~kg}(n=61, \Sigma 15)$, equally disseminated between the road vicinity and the more remote areas. High relative uncertainty due to the heterogeneity of the PAH content database for agricultural lands was observed. In forested areas, the PAH stock amounted to $\mathrm{S} 11=1.0 \pm 0.3 \times 10^{6} \mathrm{~kg}(n=26)$ with a smaller portion $(12 \%)$ located close to roads. For urban and industrial areas, the PAH amount reached S12 = $1.8 \pm 0.6 \times 10^{6} \mathrm{~kg}(n=45)$. Because further investigation on the relationship between the road traffic and the additional PAH stocks in the vicinity would be necessary to correctly quantify the pollutant amounts in the areas concerned, the stock estimation was awarded a grade of 2 . In addition, the flux of PAHs spread with urban sludge was estimated based on the population, leading to a total amount of $\mathrm{F} 13_{\#}=310 \mathrm{~kg} \mathrm{year}^{-1}(\Sigma 13)$. 


\subsubsection{Soil Erosion}

The flux of PAH transferred from topsoils to the river was estimated by matching the land use map, the average PAH contents and erosion rates estimated across the area [18]. Thus, the PAH erosion fluxes reached F15 $=1,330 \pm 1,010 \mathrm{~kg}_{\text {year }}{ }^{-1}$ $(\Sigma 15)$ for agricultural lands, F16 $=34 \pm 10 \mathrm{~kg} \mathrm{year}^{-1}(\Sigma 15)$ for forests and $\mathrm{F} 17+\mathrm{F} 18=30 \pm 9 \mathrm{~kg} \mathrm{year}^{-1}(\Sigma 15)$ for urban and industrial areas. Consequently, the overall erosion flux from soils was about $1,400 \pm 1,030 \mathrm{~kg} \mathrm{year}^{-1}(\Sigma 15)$. As for the soil stock estimation, a high mathematical uncertainty due to the heterogeneity of the PAH content database for agricultural lands was observed. Moreover, this erosion flux was estimated from PAH content in soils instead of eroded particles because no other data were available. This method did not consider a potential enrichment process during erosion due to particle sorting. Yet, previous laboratory experiments reported PAH-enriched eroded particles by a factor up to 3 [57, 58]. However, this enrichment process has never been investigated at the catchment scale, and it could not be taken into account in this estimation. Consequently, this flux estimation constitutes a rough estimation, and it was awarded a quality grade of 1 . In addition, the PAH transfer to the deep soil horizons and to groundwater was not quantified. However, because of the PAH retention in topsoil horizon [52, 53], vertical flux of PAHs within the soils was ignored.

\subsubsection{Sediment Dredging}

To estimate the fluxes related to sediment dredging in the main stem of the Seine River basin, the mass of collected material was multiplied by values of the PAH contamination of sediment. The data of 95 samples were provided by the French department of waterways, which is responsible for supervising dredging in the Seine River basin. The flux of PAHs removed from the stems with the dredged material amounted to $\mathrm{F} 25 \mathrm{a}=660 \pm 70 \mathrm{~kg}$ year $^{-1}$ with $6 \%\left(\mathrm{~F} 25 \mathrm{~b}=40 \pm 4 \mathrm{~kg}_{\mathrm{year}}{ }^{-1}\right)$ of it being spread over agricultural areas. Since the volume of sediment, the percentage of dry matter, the PAH content in the sediment and the purpose of the dredge material were known for each operation, the flux estimation was awarded a grade of 4 .

\subsubsection{Storage in Reservoirs and Floodplains}

To quantify the amount of PAHs (Fig. 4) annually stored in reservoirs (F23a), on river beds (F23b) and over floodplains (F24), the sedimentation rates were multiplied by the PAH content in suspended sediment (SS) randomly drawn in the database. As the floodplain and the reservoirs were located upstream of the Paris conurbation, the database was limited to SS samples collected in the uppermost parts of the Seine River basin. Finally, 104 samples from four studies were available $[9,11,59,60]$. The annual flux of PAHs from the rivers towards the reservoirs and 


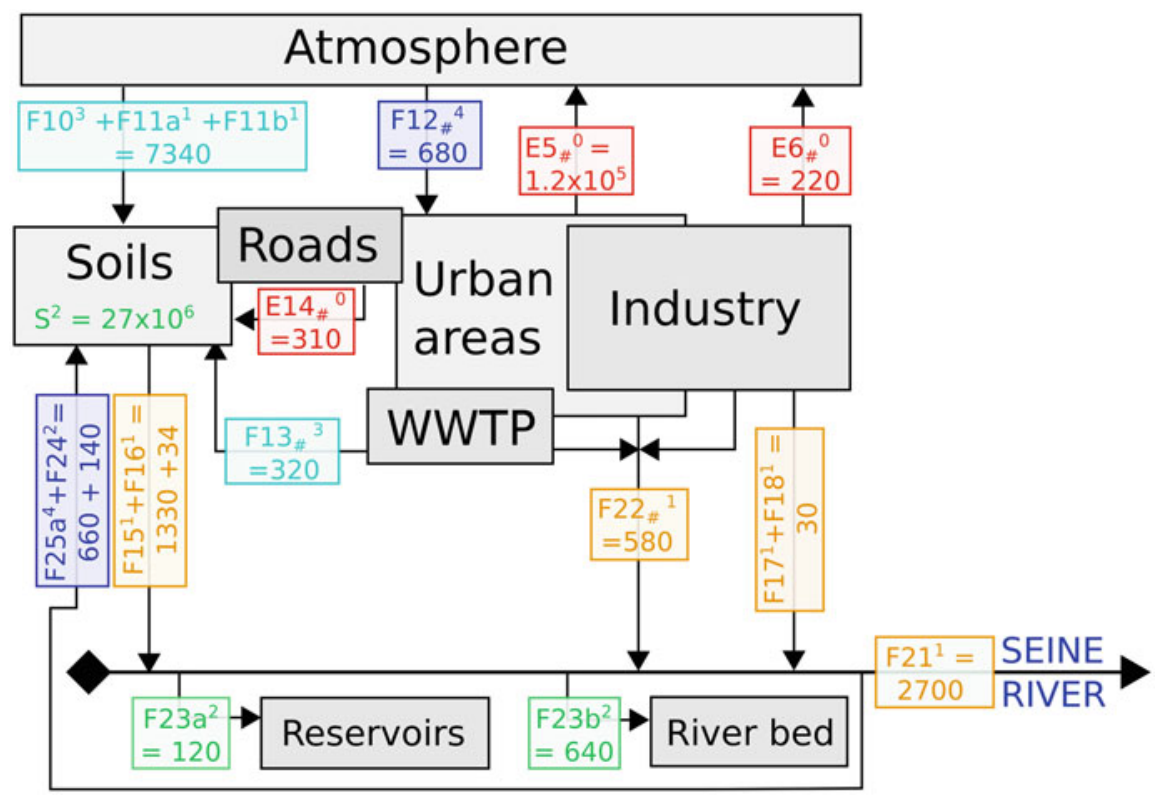

Fig. 4 PAH fluxes at the Seine River basin scale $\left(\mathrm{kg} \mathrm{year}^{-1}\right) . F$ flux calculation based on actual PAH content measurement in Paris conurbation, $E$ based on economic data or pollutant quantification in a similar environment, $F_{\#}$ or $E_{\#}$ flux based on the estimation at the Paris conurbation scale. Quality grade in superscript from 0 (worst, in red) to 4 (best, deep blue). E5 and E6 domestic and industrial emissions, F10, F11 $a$ and F12 atmospheric deposit over agricultural, forested and urban lands, $E 11 b$ forest filter effect, $S$ stocks $(\mathrm{kg})$ in soils, $F 13$ spreading of urban sludge, $E 14$ road runoff outside of urban areas, F15, F16, F17 and F18 erosion from agricultural, forested, urban and industrial lands, F22 releases from the sewer system and the WWTP to the Seine River, F23a and $F 23 b$ storage in reservoirs and on the river bed, $F 24$ flood deposits, $F 25$ river dredging

the floodplains totalled F23a $=120 \pm 10 \mathrm{~kg} \mathrm{year}^{-1}$ and F24 $=140 \pm 11 \mathrm{~kg} \mathrm{year}^{-1}$ $(\Sigma 15)$, respectively. The entire database of PAH contents in sediment $(n=183)$ was used to quantify the storage on river beds, although a greater weight was given to samples collected upstream of the Paris conurbation because $92 \%$ of the waterbody area was located upstream of the urban areas. The estimated amount of PAHs stored on the river bed was $\mathrm{F} 23 \mathrm{~b}=640 \pm 50 \mathrm{~kg}_{\text {year }}{ }^{-1}(\Sigma 15)$. The flux estimations were marred by uncertainty due to the difficulty properly quantifying the amount of sediment being deposited every year. However, the deposition rates were consistent with the amount of material delivered to the Seine River through erosion and the SS flux at the study area outlet. Moreover, the database was complete enough to ensure the good spatial and temporal representativeness of the PAH contents in upstream $\mathrm{SS}$. Therefore, the flux estimations were awarded a grade of 2 . 


\subsubsection{Flux Transported by the Seine River}

To investigate the PAH flux within the Seine River, calculations were based on concentrations measured independently in the particulate and the aqueous phases. The databases for the particulate and the dissolved fluxes of PAHs contained 15 samples from two studies [9, 60] and 11 samples from two studies [8, 60]. The annual PAH flux was estimated by attributing random values of the PAHs drawn from the databases to the monthly aqueous and solid fluxes. Finally, the total PAH flux reached F21 = 2,700 $\pm 550 \mathrm{~kg}_{\text {year }}^{-1}(\Sigma 15)$, the largest part $(77 \%)$ of it being in the particulate phase. This result was consistent with a previous publication that reported an estimation of the PAH inputs to the Seine River mouth ranging from 2000 to $2,535 \mathrm{~kg} \mathrm{year}^{-1}$ over the 2009-2013 period [61]. However, the limited number of samples did not allow for a correct investigation of the relationships between the PAH contents and the hydrological parameters, especially SS concentrations. Due to sampling difficulties, few data were available to quantify PAHs in the dissolved and particulate phases for the flood period downstream of the Paris conurbation. Contamination data measured during the low-flow period were therefore used for the flood period. Yet, previous studies have reported an increase in PAH contents in river water during floods [62] by a factor 2 for upstream sampling sites. This flux might therefore have been underestimated by about $30 \%$. Considering the low number of samples, this flux estimation was awarded a grade of 1.

\subsubsection{Estimation of Urban Fluxes at the Basin Scale}

PAH atmospheric emissions (Fig. 4) were quantified based on source spatial inventory established by INERIS, as previously described. The emissions from domestic and industrial sources were estimated at approximately E5 $5_{\#}=122$ tons year $^{-1}$ and $\mathrm{E}_{\#}=220 \mathrm{~kg}_{\text {year }}{ }^{-1}$, respectively. The atmospheric deposition over urban areas was estimated considering the whole urban surface $\left(4,020 \mathrm{~km}^{2}\right)$ and by integrating complementary data collected at other urban areas [11] into the bulk deposition database $(n=115)$. No significant change was measured in the concentrations between the four sampling sites (Kruskal-Wallis test, $p=0.27$ ). The total fallout over urban areas totalled F12 $=680 \pm 153 \mathrm{~kg} \mathrm{year}^{-1}(\Sigma 15)$.

Scarce data were available to quantify other urban fluxes at the basin scale. In particular, only a few studies investigated the PAH concentrations in the sewer systems outside of the Paris conurbation [12, 63]. However, the concentrations measured in the Paris conurbation were consistent with data reported elsewhere in France and Europe [32]. Since these fluxes were estimated based on the average wastewater produced per capita, it was assumed that the calculations made at the Paris conurbation scale could be used to estimate the urban fluxes at the entire basin scale by taking into account the population considered at the different spatial scales. This approach was reasonable for most urban fluxes, except for the runoff contribution because changes in the population density led to a lower runoff coefficient but 
also to greater vehicle use. Accordingly, it was assumed that the urban runoff flux at the entire basin scale could be estimated proportionally to the total population but that the runoff specifically related to the road runoff outside of urban areas should be quantified independently (detailed below). Finally, at the basin scale investigated, the urban releases were $F 22 \mathrm{c}_{\#}=170 \pm 20 \mathrm{~kg}_{\text {year }}{ }^{-1}(\Sigma 15)$ and $\mathrm{F}^{2} 2 \mathrm{~d}_{\#}=70 \pm 10 \mathrm{~kg}$ year $^{-1}(\Sigma 15)$ for separate and combined sewer discharge, respectively. The direct discharges of PAHs from industries to rivers were estimated at $E 22 \mathrm{~g}_{\#}=310 \pm 90 \mathrm{~kg}$ year $^{-1}(\Sigma 15)$. Finally, the PAH flux within the WWTP effluents reached $\mathrm{F}_{22 \mathrm{f}_{\#}}=30 \pm 6 \mathrm{~kg} \mathrm{year}^{-1}(\Sigma 15)$. Thus, the amount of PAHs released from the urban areas to the river system totalled F22 $(\Sigma 15)$.

\section{Discussion}

The estimated fluxes at both area scales investigated are summarised in Fig. 4.

The PAH flux to the atmosphere was dominated by household heating and road traffic (E5). The atmospheric deposition estimated at the Paris conurbation scale (F12) reached $2 \%$ of the emission quantification based on economic data (E5 + E6). At the entire basin scale, the atmospheric fallout $(\mathrm{F} 10+\mathrm{F} 11 \mathrm{a}+\mathrm{F} 11 \mathrm{~b}+\mathrm{F} 12 \#)$ reached 8 tons year ${ }^{-1}$ and accounted for only $6.5 \%$ of the emissions. This disparity between emissions and atmospheric deposition was unexpected, and it may stem from the difference in the calculation methods, where the estimation of emissions from economic data required the use of emission factors that may be poorly defined, and the measurement of atmospheric deposition may be biased due to underestimation of the gaseous exchanges [64]. In addition, environmental processes such as long-range transportation outside of the investigated area or photo-oxidation resulting in PAH degradation in the atmosphere $[65,66]$ could also partly explain that the deposition flux is far lower than the emissions flux.

The flux related to urban runoff across the investigated area (F12e) was similar to atmospheric deposition. When considering only the impervious area, the fallout flux only accounted for $22 \%$ of the estimated runoff flux, thereby suggesting that remobilisation of pollutants deposited on roofs and roads was the main process of runoff contamination. This result was consistent with previously published work [10] depicting runoff flux as four times higher than deposition flux for a small residential catchment.

The mass balance of PAHs at the Paris conurbation sewer system scale was very consistent. Indeed, the sum of incoming PAH fluxes $(F 22 a+F 12 e+F 12 f+E 22 h)$ to the sewer system was $1,350 \pm 310 \mathrm{~kg} \mathrm{year}^{-1}$, while the sewer outflows $(\mathrm{F} 22 \mathrm{c}+\mathrm{F} 22 \mathrm{~d}+\mathrm{F} 22 \mathrm{i}+\mathrm{F} 22 \mathrm{e})$ amounted to $1,360 \pm 20 \mathrm{~kg} \mathrm{year}^{-1}$ (Fig. 2). This approach was made possible by the SIAAP's thorough knowledge of the collected and treated wastewater volumes across the Paris conurbation. The result showed that the three main PAH sources, i.e. the domestic and industrial wastewater and the runoff on impervious surfaces, contributed equally to the PAH supplies to the 
sewer system. In the mass balance analysis for urban areas, the fluxes of PAHs released by industries constituted the main uncertainty. To refine these results, further investigations on the PAH concentrations in industrial effluents are required.

A specific investigation on the WWTP incoming flux (F22e) showed that separate sewers only accounted for $9 \%$ of annual PAH load to the WWTPs, while supplies from the combined sewer system reached $15 \%$ and $76 \%$ during dry and wet weather flows, respectively. It was assumed that the wet weather supply of PAHs was directly related to sewer sediment remobilisation rather than runoff [67].

When estimated at the WWTP scale, the fluxes related to sludge and effluents, respectively, amounted to $55 \%(\Sigma 13)$ and $2 \%(\Sigma 15)$ of the incoming flux, suggesting that approximately $43 \%$ of PAHs were degraded or volatilised during the treatment process. This proportion of PAHs in sludge was in agreement with previously published results [68], but the amount of PAHs released through effluent discharge was about 15 times lower. This result could be explained because the database was in part collected at the Seine-Centre WWTP characterised by high suspended matter removal efficiency, which may not be fully representative of the other WWTPs.

The overall discharge of PAHs into the Seine River system, including both WWTP effluents and overflows from the sewer system (F22c + F22d + F22f + E22g) within the Paris conurbation, reached $410 \pm 110 \mathrm{~kg}$ year ${ }^{-1}$. The main uncertainties on this flux estimation lay in data related to the characterisation of industrial and WWTP effluents. At the entire basin scale, the quality of this estimation was degraded because of the lack of information on the wastewater volumes and on the efficiency of the small-capacity WWTPs. This observation can be generalised for all the environmental fluxes since data were scarce for the rural part of the basin. A substantial study would be necessary to gather all the required information and properly estimate the flux at this scale.

Agricultural lands, forests and urban areas accumulated 72\%, 19\% and 9\%, respectively, of the total atmospheric deposition. The forest filter effect (F11b) totalled $20 \%$ of the direct deposition flux over forest areas. In comparison, the PAH stocks in soils were distributed between agricultural lands $(89 \%)$, urban areas (7\%) and forests (4\%). The low values of the inputs to the stock ratio in soils suggest that the PAH accumulation occurred over a long period of time and that biodegradation processes were not significant. Consequently, PAHs constitute a very persistent pollution within the River Seine basin.

The erosion-related flux was estimated at $1400 \mathrm{~kg} \mathrm{year}^{-1}$, but the relationship between the PAH contents in soil and in eroded particles could not be specifically investigated. A potential enrichment process occurring during erosion could not be quantified. Yet, a previous study has shown that the PAH content is much higher in suspended sediment than in the surrounding soils even in the most remote rural catchment [11]. The overall flux of PAHs stored within the river system $(\mathrm{F} 23 \mathrm{a}+\mathrm{F} 23 \mathrm{~b})$ was estimated at $760 \pm 70 \mathrm{~kg} \mathrm{year}^{-1}$, and it reached about $28 \%$ of the PAH flux carried downstream of the study area outlet (F21).

Overall, the soil erosion was the main source of PAHs in the Seine River, while urban release constituted a significant but smaller source. The PAH inputs to the Seine River $\left(\mathrm{F} 15+\mathrm{F} 16+\mathrm{F} 17+\mathrm{F} 18+\mathrm{F} 22_{\#}\right)$ were about twofold lower than the PAH 
flux carried downstream of the study area outlet (F21). Several hypotheses can be considered to explain this gap. Firstly, PAH fluxes from the urban areas could have been underestimated. More specifically, the change in spatial scale constitutes a major source of uncertainty because most of the calculation parameters were poorly known at the entire basin scale. Secondly, and as previously described, an enrichment process that would occur during erosion could drastically increase the PAH flux from soil to rivers. Thus, an average enrichment by a factor 3 [57] would balance the PAH inputs and outputs. Finally, the mass balance could be right and the Seine River basin may currently be undergoing a decontamination phase involving the remobilisation of ancient and more contaminated sediment. This process can explain the short-term difference between pollutant inputs and outputs, as was already suggested for metals [69].

\section{Conclusions and Perspectives}

For the first time in the literature, a mass balance at a large spatial scale, i.e. the upper basin of the Seine River, was attempted for PAHs. This approach was enlightening in terms of both the environmental fate of PAHs and the priority research areas to complete these investigations.

Except for PAH emissions, all the estimated fluxes had consistent orders of magnitude. Although mistakes in the flux estimations could not be excluded, the difference between the amounts of PAHs emitted to the atmosphere and deposited from it suggests that physico-chemical processes still need to be investigated. In particular, the fate of PAHs in the atmosphere is poorly known. A number of studies have focused on the process responsible for chemical oxidation and photo-oxidation of atmospheric PAHs, but the phenomenon has never been quantified at a large spatial scale. Such an investigation would be challenging but would provide significant knowledge on a process that may drastically limit environmental PAH contamination. From a public perspective, it would be advantageous to quantify the deposition of the compounds arising from these degradation processes because they have been shown to constitute a health issue.

At the Paris conurbation scale, the sewer system inputs and outputs closely matched given the well-established wastewater and sludge mass balances. The result showed the importance of runoff and wastewater management to deal with PAH fluxes. In particular, the treatment processes implemented at the WWTPs have proven their efficiency in PAH removal, thereby drastically limiting the flux being released through WWTP effluents. However, two major sources of uncertainty remained. Firstly, the PAH fluxes related to industrial discharge to the sewers and rivers were poorly known. Since neither the wastewater volume nor the PAH concentrations were quantified, considerable work would be required to overcome this issue despite the current deindustrialisation of the basin. Because various industries are reported be responsible for different effluent contaminations, a specific inventory would be necessary. Secondly, more data on the PAH concentrations 
in the WWTP effluents would be necessary to validate or improve the quantification of the flux discharged to the Seine River. This investigation would even be crucial at the Seine River basin scale because small-capacity WWTPs vary greatly in efficiency. A similar consideration can be made for most of the urban fluxes because various inconsistencies appeared in the mass balance at the Seine River basin scale due to the lack of representative databases for such an extended area. Consequently, research is still required to precisely quantify the PAH flux in the urban parts of the basin other than the Paris conurbation. In particular, fluxes related to the sewer system and the WWTP are poorly known in less densely populated areas. This difficulty was highlighted by the road runoff estimation. To properly quantify this flux, one should investigate the relationship between the PAH concentrations in the runoff water, the runoff volume and the daily vehicle traffic.

In addition, certain fluxes could not be estimated based on the compiled databases, especially the environmental degradation fluxes. However, according to our PAH budgets, only degradation within the atmosphere would be significant. Indeed, the long-term contaminations of the soils which constituted the main PAH reservoir suggest that no significant degradation occurs in this compartment. This result could be reinforced by long-term monitoring of soils. Similarly, PAH volatilisation from soils was not quantified. More generally, the gaseous exchanges at the ground-plantatmosphere interface required further investigation.

Finally, there is a serious need to investigate the enrichment process to refine the PAH flux related to soil erosion at the Seine River basin scale. Indeed, this parameter plays a crucial role in determining if the Seine River basin is currently balanced in terms of PAH input and outputs or if it is currently undergoing a decontamination phase. Contaminated sediment stored in the river bed and in reservoirs is likely to be remobilised during massive flood events such as the one that occurred in June 2016 [69]. A long-term survey of the Seine River would be required to precisely quantify the average annual fluxes in the Seine system. In particular, closer monitoring of flood events would drastically improve the accuracy of the estimation of the PAH flux being carried by the Seine River downstream of Paris (F21).

Acknowledgements This work was conducted in the framework of the PIREN-Seine research programme (www.piren-seine.fr), a component of the Zone Atelier Seine within the international Long Term Socio-Ecological Research (LTSER) network.

\section{References}

1. Meybeck M, Lestel L, Bonté P et al (2007) Historical perspective of heavy metals contamination $(\mathrm{Cd}, \mathrm{Cr}, \mathrm{Cu}, \mathrm{Hg}, \mathrm{Pb}, \mathrm{Zn})$ in the Seine River basin (France) following a DPSIR approach (1950-2005). Sci Total Environ 375:204-231

2. Thévenot DR, Moilleron R, Lestel L et al (2007) Critical budget of metal sources and pathways in the Seine River basin (1994-2003) for Cd, Cr, Cu, Hg, Ni, Pb and Zn. Sci Total Environ 375:180-203 
3. Mastrangelo G, Fadda E, Marzia V (1996) Polycyclic aromatic hydrocarbons and cancer in man. Environ Health Perspect 3:1166-1170

4. Bouloubassi I, Saliot A (1991) Composition and sources of dissolved and particulate Pah in surface waters from the Rhone Delta (nw Mediterranean). Mar Pollut Bull 22:588-594

5. Ravindra K, Sokhi R, Vangrieken R (2008) Atmospheric polycyclic aromatic hydrocarbons: source attribution, emission factors and regulation. Atmos Environ 42:2895-2921

6. Moreau-Guigon E, Alliot F, Gaspéri J et al (2016) Seasonal fate and gas/particle partitioning of semi-volatile organic compounds in indoor and outdoor air. Atmos Environ 147:423-433

7. Gateuille D, Evrard O, Lefevre I et al (2014) Combining measurements and modelling to quantify the contribution of atmospheric fallout, local industry and road traffic to PAH stocks in contrasting catchments. Environ Pollut 189:152-160

8. Tusseau-Vuillemin M-H, Gourlay C, Lorgeoux C et al (2007) Dissolved and bioavailable contaminants in the Seine River basin. Sci Total Environ 375:244-256

9. Ollivon D, Garban B, Chesterikoff A (1995) Analysis of the distribution of some polycyclic aromatic hydrocarbons in sediments and suspended matter in the river Seine (France). Water Air Soil Pollut 81:135-152

10. Bressy A, Gromaire M-C, Lorgeoux C et al (2012) Towards the determination of an optimal scale for stormwater quality management: micropollutants in a small residential catchment. Water Res 46:6799-6810

11. Gateuille D, Evrard O, Lefevre I et al (2014) Mass balance and decontamination times of Polycyclic Aromatic Hydrocarbons in rural nested catchments of an early industrialized region (Seine River basin, France). Sci Total Environ 470-471:608-617

12. Motelay-Massei A, Ollivon D, Garban B et al (2007) Fluxes of polycyclic aromatic hydrocarbons in the Seine estuary, France: mass balance and role of atmospheric deposition. Hydrobiologia 588:145-157

13. Rodenburg LA, Valle SN, Panero MA et al (2010) Mass balances on selected polycyclic aromatic hydrocarbons in the New York-New Jersey Harbor. J Environ Qual 39:642-653

14. Froger C, Quantin C, Gasperi J et al (2019) Impact of urban pressure on the spatial and temporal dynamics of PAH fluxes in an urban tributary of the Seine River (France). Chemosphere 219:1002-1013

15. Mailler R (2015) Devenir des micropolluants prioritaires et émergents dans les filieres conventionnelles de traitement des eaux résiduaires urbaines des grosses collectivités (filières eau et boues), et au cours du traitement tertiaire au charbon actif. Université ParisEst, Champs-sur-Marne. https://hal-enpc.archives-ouvertes.fr/tel-01226483/

16. Kafi M, Gasperi J, Moilleron R et al (2008) Spatial variability of the characteristics of combined wet weather pollutant loads in Paris. Water Res 42:539-549

17. Delmas M, Cerdan O, Mouchel J-M, Garcin M (2009) A method for developing a large-scale sediment yield index for European river basins. J Soils Sediments 9:613-626

18. Delmas M, Cerdan O, Cheviron B et al (2012) Sediment export from French rivers to the sea. Earth Surf Process Landf 37:754-762

19. Terzaghi E, Wild E, Zacchello G et al (2013) Forest filter effect: role of leaves in capturing/ releasing air particulate matter and its associated PAHs. Atmos Environ 74:378-384

20. Ollivon D, Garban B, Blanchard M et al (2002) Vertical distribution and fate of trace metals and persistent organic pollutants in sediments of the Seine and Marne rivers (France). Water Air Soil Pollut 134:57-79

21. Blanchard M, Teil M-J, Guigon E et al (2007) Persistent toxic substance inputs to the river Seine basin (France) via atmospheric deposition and urban sludge application. Sci Total Environ 375:232-243

22. Teil M-J, Moreau-Guigon E, Blanchard M et al (2016) Endocrine disrupting compounds in gaseous and particulate outdoor air phases according to environmental factors. Chemosphere 146:94-104

23. Garban B, Blanchoud H, Motelay-Massei A et al (2002) Atmospheric bulk deposition of PAHs onto France: trends from urban to remote sites. Atmos Environ 36:5395-5403 
24. Gasperi J, Sebastian C, Ruban V et al (2014) Micropollutants in urban stormwater: occurrence, concentrations, and atmospheric contributions for a wide range of contaminants in three French catchments. Environ Sci Pollut Res 21:5267-5281

25. Zgheib S, Moilleron R, Chebbo G (2011) Influence of the land use pattern on the concentrations and fluxes of priority pollutants in urban stormwater. Water Sci Technol 64:1450-1458

26. Zgheib S, Moilleron R, Chebbo G (2012) Priority pollutants in urban stormwater: part 1 - case of separate storm sewers. Water Res 46:6683-6692

27. Ngabe B, Bidleman TF, Scott GI (2000) Polycyclic aromatic hydrocarbons in storm runoff from urban and coastal South Carolina. Sci Total Environ 255:1-9

28. Menzie CA, Hoeppner SS, Cura JJ et al (2002) Urban and suburban storm water runoff as a source of polycyclic aromatic hydrocarbons (PAHs) to Massachusetts estuarine and coastal environments. Estuaries 25:165-176

29. Hannouche A, Chebbo G, Joannis C et al (2017) Stochastic evaluation of annual micropollutant loads and their uncertainties in separate storm sewers. Environ Sci Pollut Res 24:28205-28219

30. Gasperi J, Rocher V, Moilleron R, Chebbo G (2005) Hydrocarbon loads from street cleaning practices: comparison with dry and wet weather flows in a parisian combined sewer system. Polycycl Aromat Compd 25:169-181

31. Gasperi J (2006) Introduction et transferts des hydrocarbures à différentes échelles spatiales dans le réseau d'assainissement parisien. Ecole Nationale des Ponts et Chaussées, Champs-surMarne. https://pastel.archives-ouvertes.fr/pastel-00002103

32. Sánchez-Avila J, Bonet J, Velasco G, Lacorte S (2009) Determination and occurrence of phthalates, alkylphenols, bisphenol A, PBDEs, PCBs and PAHs in an industrial sewage grid discharging to a Municipal Wastewater Treatment Plant. Sci Total Environ 407:4157-4167

33. Blanchard M, Teil MJ, Ollivon D et al (2004) Polycyclic aromatic hydrocarbons and polychlorobiphenyls in wastewaters and sewage sludges from the Paris area (France). Environ Res 95:184-197

34. Mailler R, Gasperi J, Rocher V et al (2013) Biofiltration vs conventional activated sludge plants: what about priority and emerging pollutants removal? Environ Sci Pollut Res 21:5379-5390

35. Teil M-J, Alliot F, Blanchard M, et al (2008) Contamination de l'Orge et de la Seine par des micropolluants organiques: PBDE, phtalates, alkylphénols et HAP sous différentes conditions hydrologiques. https://hal.archives-ouvertes.fr/hal-00766528

36. Blanchard M, Teil M-J, Ollivon D et al (2001) Origin and distribution of polyaromatic hydrocarbons and polychlorobiphenyls in urban effluents to wastewater treatment plants of the Paris area (FRANCE). Water Res 35:3679-3687

37. Gasperi J, Zgheib S, Cladière M et al (2012) Priority pollutants in urban stormwater: part 2 case of combined sewers. Water Res 46:6693-6703

38. Rocher V, Azimi S, Moilleron R, Chebbo G (2004) Hydrocarbons and heavy metals in the different sewer deposits in the 'Le Marais' catchment (Paris, France): stocks, distributions and origins. Sci Total Environ 323:107-122

39. Rocher V, Garnaud S, Moilleron R, Chebbo G (2004) Hydrocarbon pollution fixed to combined sewer sediment: a case study in Paris. Chemosphere 54:795-804

40. Gasperi J, Moilleron R, Chebbo G (2006) Spatial variability of polycyclic aromatic hydrocarbon load of urban wet weather pollution in combined sewers. Water Sci Technol 54:185-193

41. Barret M, Carrère H, Delgadillo L, Patureau D (2010) PAH fate during the anaerobic digestion of contaminated sludge: do bioavailability and/or cometabolism limit their biodegradation? Water Res 44:3797-3806

42. Busetti F, Heitz A, Cuomo M et al (2006) Determination of sixteen polycyclic aromatic hydrocarbons in aqueous and solid samples from an Italian wastewater treatment plant. J Chromatogr A 1102:104-115

43. Vogelsang C, Grung M, Jantsch TG et al (2006) Occurrence and removal of selected organic micropollutants at mechanical, chemical and advanced wastewater treatment plants in Norway. Water Res 40:3559-3570 
44. Fatone F, Di Fabio S, Bolzonella D, Cecchi F (2011) Fate of aromatic hydrocarbons in Italian municipal wastewater systems: an overview of wastewater treatment using conventional activated-sludge processes (CASP) and membrane bioreactors (MBRs). Water Res 45:93-104

45. Horstmann M, McLachlan MS (1998) Atmospheric deposition of semivolatile organic compounds to two forest canopies. Atmos Environ 32:1799-1809

46. Simonich SL, Hites RA (1994) Vegetation-atmosphere partitioning of polycyclic aromatic hydrocarbons. Environ Sci Technol 28:939-943

47. Moreau-Guigon E, Alliot F, Gasperi J, et al (2015) Contamination de l'atmosphère par les composés perturbateurs endocriniens en Ile-de-France. https://hal-enpc.archives-ouvertes.fr/ hal-01162348

48. Augusto L, Ranger J, Binkley D, Rothe A (2002) Impact of several common tree species of European temperate forests on soil fertility. Ann For Sci 59:233-253

49. Nadal M, Schuhmacher M, Domingo JL (2004) Levels of PAHs in soil and vegetation samples from Tarragona County, Spain. Environ Pollut 132:1-11

50. Kipopoulou AM, Manoli E, Samara C (1999) Bioconcentration of polycyclic aromatic hydrocarbons in vegetables grown in an industrial area. Environ Pollut 106:369-380

51. Moreau-Guigon E, Gaspéri J, Alliot F, et al (2012) Contamination de l'air par les contaminants organiques, bioindication et conséquences sur la contamination des sols. http://piren16.metis. upmc.fr/?q=webfm_send/1164

52. Enell A, Reichenberg F, Warfvinge P, Ewald G (2004) A column method for determination of leaching of polycyclic aromatic hydrocarbons from aged contaminated soil. Chemosphere 54:707-715

53. Krauss M, Wilcke W, Zech W (2000) Polycyclic aromatic hydrocarbons and polychlorinated biphenyls in forest soils: depth distribution as indicator of different fate. Environ Pollut 110:79-88

54. Doick KJ, Klingelmann E, Burauel P et al (2005) Long-term fate of polychlorinated biphenyls and polycyclic aromatic hydrocarbons in an agricultural soil. Environ Sci Technol 39:3663-3670

55. Gaspéri J, Ayrault S, Moreau-Guigon E et al (2018) Contamination of soils by metals and organic micropollutants: case study of the Parisian conurbation. Environ Sci Pollut Res 25:23559-23573

56. Crépineau C, Rychen G, Feidt C et al (2003) Contamination of pastures by polycyclic aromatic hydrocarbons (PAHs) in the vicinity of a highway. J Agric Food Chem 51:4841-4845

57. Zheng Y, Luo X, Zhang W et al (2012) Enrichment behavior and transport mechanism of soil-bound PAHs during rainfall-runoff events. Environ Pollut 171:85-92

58. Luo X, Zheng Y, Wu B et al (2013) Impact of carbonaceous materials in soil on the transport of soil-bound PAHs during rainfall-runoff events. Environ Pollut 182:233-241

59. Gasperi J, Garnaud S, Rocher V, Moilleron R (2009) Priority pollutants in surface waters and settleable particles within a densely urbanised area: case study of Paris (France). Sci Total Environ 407:2900-2908

60. Gaspéri J, Moreau-Guigon E, Labadie P, et al (2010) Contamination de la Seine par les micropolluants organiques: évolution selon les conditions hydriques et l'urbanisation

61. Seine-Aval G, Fisson C (2015) Flux en contaminants à l'estuaire de la Seine. 34. https://www. seine-aval.fr/wp-content/uploads/2017/01/Fisson-2015-Flux.pdf

62. Agence de l'eau Seine-Normandie, Chevreuil M, Programme interdisciplinaire de recherche sur l'environnement de la Seine (2009) La micropollution organique dans le bassin de la Seine maîtriser l'impact des molécules créées par l'homme. Agence de l'eau Seine-Normandie, Nanterre. http://piren16.metis.upmc.fr/?q=webfm_send/824

63. Motelay-Massei A, Garban B, Tiphagne-larcher K et al (2006) Mass balance for polycyclic aromatic hydrocarbons in the urban watershed of Le Havre (France): transport and fate of PAHs from the atmosphere to the outlet. Water Res 40:1995-2006

64. Demircioglu E, Sofuoglu A, Odabasi M (2011) Particle-phase dry deposition and air-soil gas exchange of polycyclic aromatic hydrocarbons (PAHs) in Izmir, Turkey. J Hazard Mater 186:328-335 
65. Ringuet J, Albinet A, Leoz-Garziandia E et al (2012) Reactivity of polycyclic aromatic compounds (PAHs, NPAHs and OPAHs) adsorbed on natural aerosol particles exposed to atmospheric oxidants. Atmos Environ 61:15-22

66. Ringuet J, Albinet A, Leoz-Garziandia E et al (2012) Diurnal/nocturnal concentrations and sources of particulate-bound PAHs, OPAHs and NPAHs at traffic and suburban sites in the region of Paris (France). Sci Total Environ 437:297-305

67. Gasperi J, Gromaire MC, Kafi M et al (2010) Contributions of wastewater, runoff and sewer deposit erosion to wet weather pollutant loads in combined sewer systems. Water Res 44:5875-5886

68. Qiao M, Qi W, Liu H, Qu J (2014) Occurrence, behavior and removal of typical substituted and parent polycyclic aromatic hydrocarbons in a biological wastewater treatment plant. Water Res 52:11-19

69. Le Gall M, Ayrault S, Evrard O et al (2018) Investigating the metal contamination of sediment transported by the 2016 Seine River flood (Paris, France). Environ Pollut 240:125-139

Open Access This chapter is licensed under the terms of the Creative Commons Attribution 4.0 International License (http://creativecommons.org/licenses/by/4.0/), which permits use, sharing, adaptation, distribution and reproduction in any medium or format, as long as you give appropriate credit to the original author(s) and the source, provide a link to the Creative Commons licence and indicate if changes were made.

The images or other third party material in this chapter are included in the chapter's Creative Commons licence, unless indicated otherwise in a credit line to the material. If material is not included in the chapter's Creative Commons licence and your intended use is not permitted by statutory regulation or exceeds the permitted use, you will need to obtain permission directly from the copyright holder.

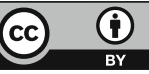

